\title{
AMELOGENESIS IMPERFECTA: A CLINICAL REPORT
}

Veena Hegde ${ }^{1}$, Sunanda Sharma ${ }^{2}$

\section{HOW TO CITE THIS ARTICLE:}

Veena Hegde, Sunanda Sharma. "Amelogenesis Imperfecta: A Clinical Report". Journal of Evolution of Medical and Dental Sciences 2015; Vol. 4, Issue 01, January 01; Page: 140-146 DOI: 10.14260/jemds/2015/23

ABSTRACT: AIM: This clinical case report describes the oral rehabilitation of a young adult female patient diagnosed with hypoplastic Amelogenesis imperfecta. SUMMARY: Amelogenesis Imperfecta is a hereditary condition that affects the formation of the enamel mineralization process of both the primary and secondary dentition. It is clinically and genetically heterogeneous group of condition that affects both the quantity and quality of the enamel structure resulting in extensive loss of tooth tissue, poor esthetics and tooth sensitivity. The main objective for the selected treatment was to enhance the esthetics, and restoring masticatory function. Treatment was divided into phases which included removal of impacted canine, lengthening of the maxillary and mandibular clinical crowns, and placement of anterior and posterior crowns.

KEYWORDS: Amelogenesis imperfecta, Esthetics, Oral rehabilitation, Porcelain laminate veneers.

INTRODUCTION: Amelogenesis imperfecta (AI) (Amelogenesis - enamel formation; imperfecta imperfecta) is a relatively rare group of inherited disorders characterized by abnormal enamel formation. ${ }^{[1]}$ The term amelogenesis imperfecta is reserved for hereditary defects of enamel that are not associated with defects in other parts of the body or other health problems. ${ }^{[2]}$ It affects the structure and clinical appearance of the enamel of all or nearly all the teeth, and which may be associated with morphologic or biochemical changes in the body.[3,4] Prevalence has been reported to vary between approximately 1: 700 to $1: 14,000 . .^{[5-8]}$

AI may be inherited in an X-linked manner or as an autosomal dominant or recessive trait ${ }^{[1,4,9]}$ AI has been broadly classified as hypoplastic and hypocalcified types in 1945, after which many classifications have evolved, some exclusively based on the phenotype, others consider phenotype as the primary determinant and the mode of inheritance as a secondary factor in diagnosis.[1-3,10-11] This enamel anomaly affects both primary and permanent dentition.[1-3] The clinical appearance depends on the type of AI, varying from the mild hypomature 'snow-capped' enamel to the more severe hereditary hypoplasia with thin, hard enamel which has a yellow-brown appearance. Depending on severity of the condition, dental problems include sensitive teeth and poor appearance due to tooth loss and staining.[12-14]

The treatment planning for patients with amelogenesis imperfecta is related to many factors: the age, socioeconomic status of the patient, the type and severity of the disorder, and the intraoral situation. ${ }^{[15]}$ A recently published survey reported the importance of treating the AI patient not only from a functional standpoint, but from a psychosocial health standpoint as well.[15]

This clinical report describes the sequenced full mouth rehabilitation of a young adult patient with hypoplastic amelogenesis imperfecta. Thus the aim of the treatment was to both restore esthetics and improve masticatory function.

CASE REPORT: A 17- year old female patient presented with the chief complaint of yellowish discoloration of teeth and unsatisfactory dental appearance (Fig. 1). As patient was minor, informed 


\section{CASE REPORT}

consent was taken from her parents. A detailed medical, dental and social history was obtained. Although her medical history did not reveal any abnormalities, her family history showed that her mother and her sister had similar dental appearance. Hard tissue examination revealed: the enamel of all the teeth was hypoplastic and teeth were yellow -brown in colour, generalized occlusal and incisal attrition with reduced crown height, palatally impacted 23 and dental caries was present in $16,25,37,46$. The surface of the teeth were rough, the enamel was absent on most areas and the underlying dentine seen was yellow-brown. Dental midline discrepancy was also observed. Minimal loss of vertical dimension was observed with a freeway space of 3-4 mm. Radiographic examination revealed palatally impacted 23 , absence of enamel and large pulp chambers in most teeth.

Based on clinical and radiographic features, a diagnosis of hereditary Amelogenesis imperfecta was made and the objectives of the treatment planned were to preserve the tooth structure, improve esthetics and masticatory function. Impressions with irreversible hydrocolloid were made to obtain diagnostic casts from Type III dental stone and the casts mounted on a semiadjustable articulator (Hanau Wide Vue) using a face-bow transfer (Fig. 2) and a centric relation record (Regisil 2X - VPS Bite Registration paste, Dentsply).The articulator was programmed using protrusive records. Occlusal scheme was developed using a customized Broadrick's occlusal plane analyzer and a diagnostic wax up was done (Fig 3,4). The incisal guidance was determined with the diagnostic wax-up.

In the first phase of treatment, oral prophylaxis was performed and palatally impacted 23 were surgically extracted. In the second phase of treatment, endodontic therapy and crown lengthening procedure were carried out for the posterior teeth. The appropriate shade was then selected using the VITA shade guide (Vita Zahnfabrik, Badsackingen, Germany) prior to preparation.

Next phase consisted of preparation of teeth: 11, 12, 13, 21, 31, 32, 41 and 42 were prepared to receive porcelain laminate veneers; $14,15,22,24,25$, for all ceramic crowns and 16, 26, 36, 46 for all metal crowns. Porcelain laminate veneers were planned for the anterior teeth, as there was minimal loss of tooth structure on the anterior teeth and also tooth sensitivity was not a complaint. Metal crowns were planned for posteriors due to reduced crown height and minimum available space.

Gingival retraction was done for prepared teeth (Fig. 5, 6) Impressions were made with double mix, single impression technique using polyvinyl siloxane (Reprosil@, Dentsply, Canada) in a custom tray. Patient was guided into centric realtion and bite registration was done using PVS bite registration paste (Regisil 2X - VPS Bite Registration paste, Dentsply).

The prepared teeth were restored with provisional crowns fabricated with Heat-cured methyl methacrylate acrylic resin, using putty indices of the diagnostic wax-up (Fig 7). These were cemented using temporary cement (Provicol, VOCO, GmbH). Face-bow transfer (Hanau spring-bow) was done to mount maxillary cast on a semi-adjustable articulator (Hanau Wide ${ }^{\mathrm{TM}}$ Vue) with the mandibular cast with the help of the bite registration record.

The final wax-up was done and a canine-guided occlusion was planned on the right and a group function on the left side, due to absence of 23 (Fig 8, 9, 10, 11). All-ceramic crowns (IPS Emax), veneers (IPS Empress ${ }^{\circledR}$ II), and metal crowns were fabricated and were tried in the patients mouth (Fig. 12). The marginal fit and esthetic appearance of the crowns and veneers were verified. In the final steps, the veneers and the crowns were cemented using resin cement (RelyX ARC Adhesive 
Resin Cement, 3M ESPE, USA) (Fig 13, 14, 15). The patient was instructed a proper oral hygiene maintenance regimen and recalls after every 6 months.

DISCUSSION: Most common congenital anomalies of dental hard tissues are the genetic defects of the enamel. In the past, treatment of AI had included extractions and fabrication of complete dentures, however, these options are radical and psychologically displeasing to the patients. Recent advances in the field of esthetics and prosthetic dentistry have enabled the restoration of function and esthetics to an acceptable level in severe AI cases.[16,17]

This case report describes a multidisciplinary approach for the treatment of AI. The established occlusal scheme was evaluated during the phase of provisional restorations. The patient was comfortable with the temporary restorations and the final restorations were also fabricated using the same putty indices.

A canine-guided occlusion was established on the right and a group function on the left side, due to absence of 23. All ceramic crowns (EMAX) were fabricated for the premolars, as along with being esthetic, this all ceramic system has strength sufficient for use in the posterior region of the mouth.

At the end of the procedure, we were able to achieve both functional and esthetic satisfaction of the patient. After a follow up of six months, the patient did not present any signs and symptoms of abnormal function and was satisfied with both function and esthetics.

CONCLUSION: This clinical report described an interdisciplinary approach of AI with the use of porcelain laminate veneers, all ceramic crowns and full metal crown, to restore the masticatory function, improve the esthetics with careful consideration of patient expectations.

ACKNOWLEDGEMENT: Authors thank hospital committee for giving necessary permission to perform the treatment and to publish the case report.

\section{REFERENCES:}

1. Weinmann JP, Svoboda JF, Woods RW (1945) hereditary disturbances of enamel formation and calcification. J Am Dent Assoc1945; 32:397-418.

2. Aldred MJ, Savarirayan R, Crawford PJM (2003) Amelogenesis imperfecta: a classification and catalogue for the 21st century. Oral Dis 9:19-23.

3. Neville BW, Damm DD, Allen CM, Bouquot JE (2002) Oral and maxillofacial pathology, 2nd edn. Elsevier, Philadelphia, pp 89-94.

4. Witkop CJ Jr. Amelogenesis imperfect, dentinigenesis imperfect and dentine dysplasia revisited: Problems in classification. J Oral Pathol 1988;17:547-53.

5. Witkop CJ, Rao SR (1971) Inherited defects in tooth structure. Birth Defects Orig Artic Ser 7:153-184.

6. Backman B, Holm AK (1986) Amelogenesis imperfecta: prevalence and incidence in a northern Swedish county. Community Dent Oral Epidemiol 14:43-47.

7. Sundell S, Koch G (1985) hereditary amelogenesis imperfecta. Epidemiology and clinical classification in a Swedish child population. Swed Dent J 9:157-169. 


\section{CASE REPORT}

8. Witkop CJ (1957) Hereditary defects in enamel and dentin. Acta Genet Stat Med 7:236- 239.

9. Chaudary M, Dixit S, Singh A, Kunte S (2009) Amelogenesis imperfecta-a report of a case and review of literature. J Oral Maxillofac pathol 13 (2): 59-101.

10. Sundell S, Valentin J (1986) hereditary aspects and classification of hereditary amelogenesis imperfecta. Community Dent Oral Epidemiol 14:211-219.

11. Aldred MJ, Crawford PJM (1988) Variable expression in amelogenesis imperfecta with taurodontism. J Oral Pathol Med 17:327-333.

12. Seow WK (1993) Clinical diagnosis and management strategies of amelogenesis imperfecta variants. Pediatr Dent 15:384-393.

13. Coffield KD, Phillips C, Brady M, Roberts MW, Strauss RP, Wright JT (2005) the psychosocial impact of developmental dental defects in people with hereditary amelogenesis imperfecta. J Am Dent Assoc 136:620-630.

14. Ayers KMS, Drummond BK, Harding WJ, Salis SG, Liston PN (2004) Amelogenesis imperfectamultidisciplinary management from eruption to adulthood. Review and case report. N Z Dent J 100:101-104.

15. Ozturk N, Sarı Z, Ozturk B (2004) an interdisciplinary approach for restoring function and esthetics in a patient with amelogenesis imperfecta and malocclusion: a clinical report. J Prosthet Den 92:112-115.

16. Coley-Smith A, Brown CJ. Case report: radical management of an adolescent with amelogenesis imperfecta. Dent Update. 1996; 23: 434-435.

17. Goodacre CJ, Guillermo B, Rungcharassaeng K, Kan JYK. Clinical complications with implants and implant prostheses. J Prosthet Dent. 2003; 90: 121-132.

doi: 10.1016/S0022-3913 (03)00212-9.

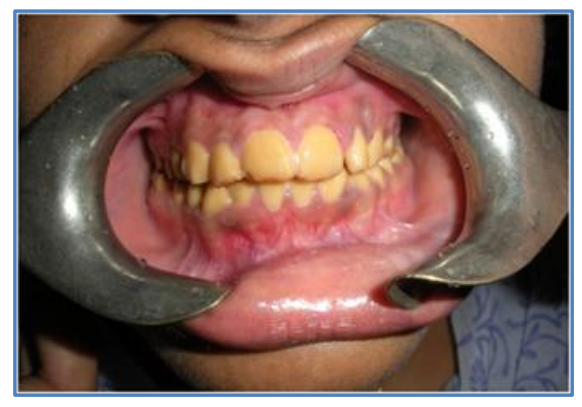

Fig. 1: Pre-operative view

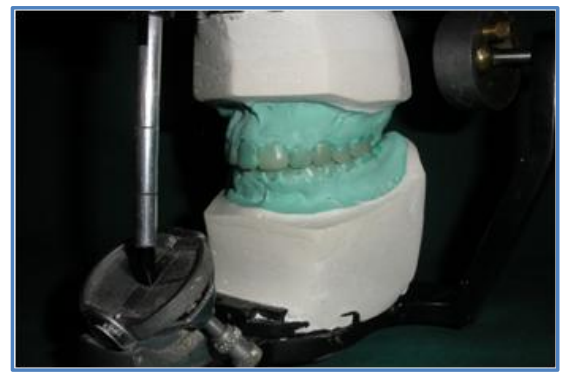

Fig. 3: Diagnostic wax up Left lateral view

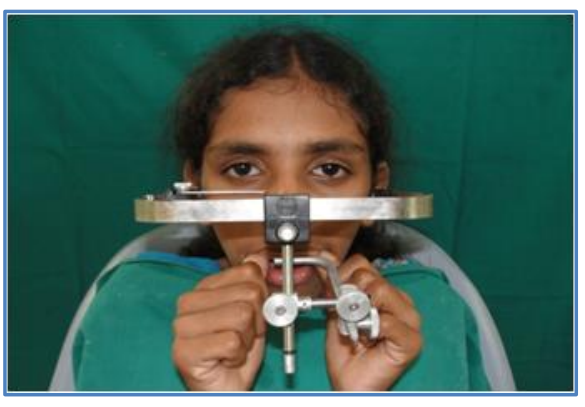

Fig. 2: Face bow transfer

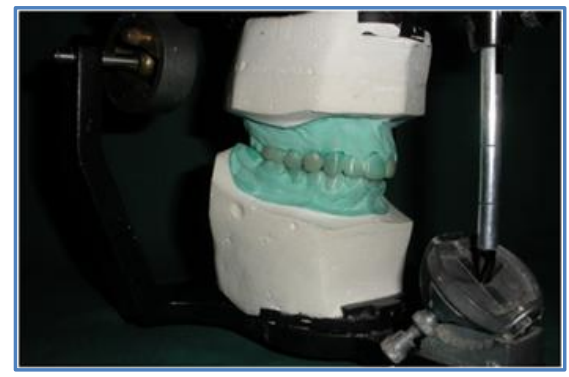

Fig. 4: Diagnostic wax up Right lateral view 


\section{CASE REPORT}

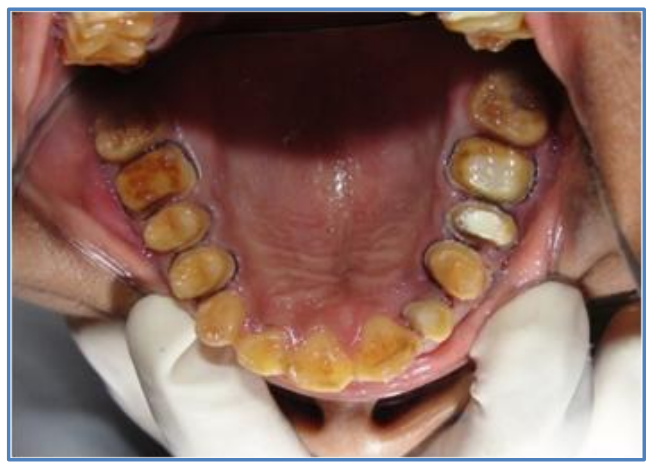

Fig. 5: Maxillary Crown preparation \& gingival retraction

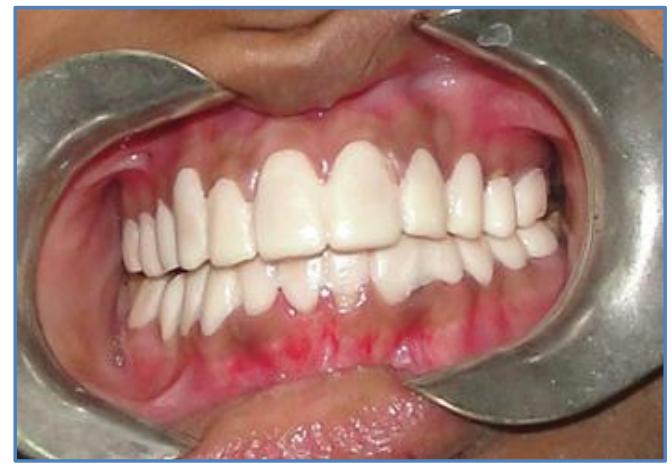

Fig. 7: Provisional restoration

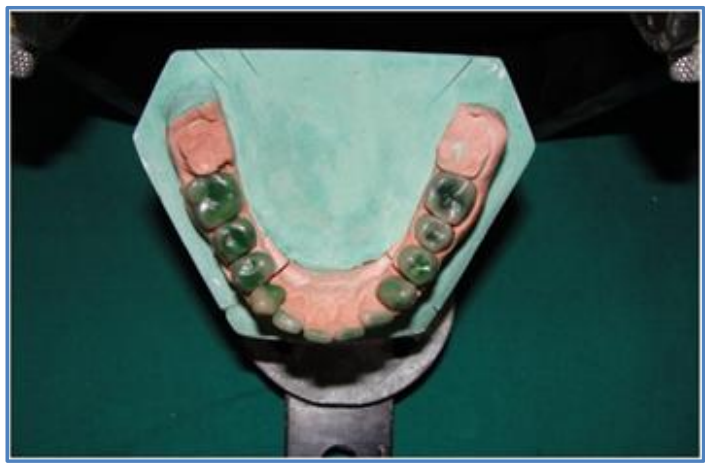

Fig. 9 Wax pattern fabrication Lower occlusal view

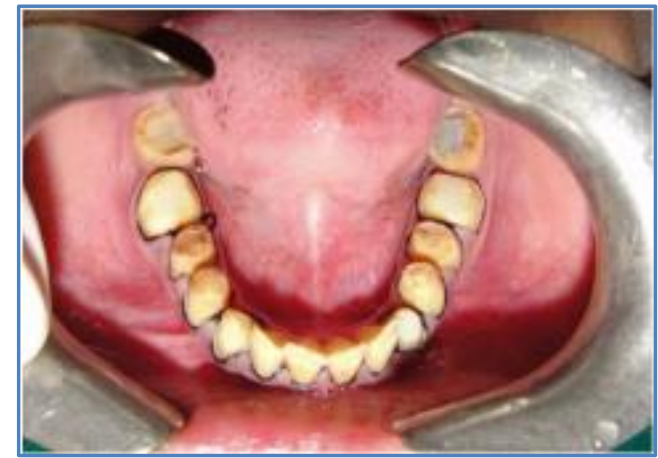

Fig. 6: Mandibular Crown preparation $\&$ gingival retraction

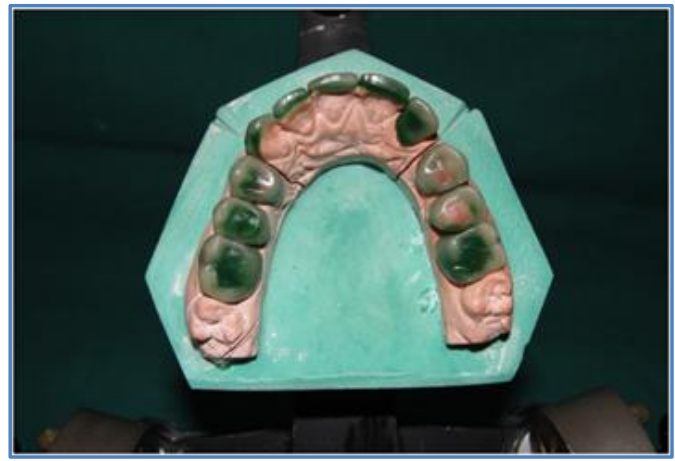

Fig. 8: Wax pattern fabrication upper occlusal view

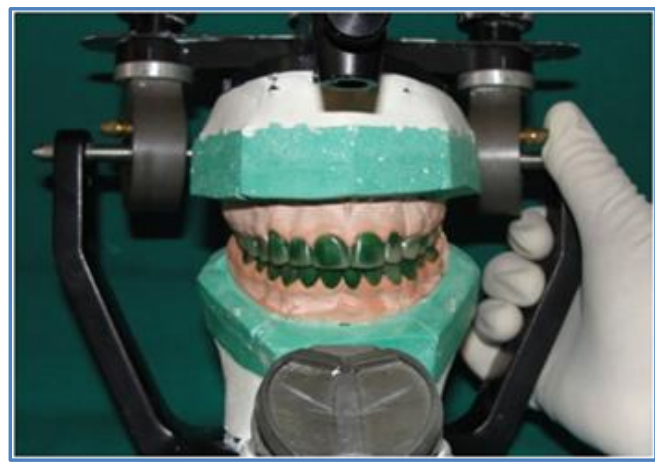

Fig.10: Wax patterns 


\section{CASE REPORT}

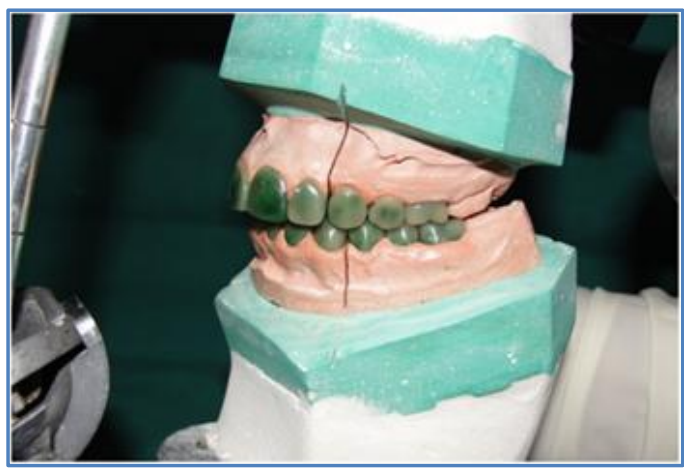

Fig. 11: Wax patterns in centric left lateral view

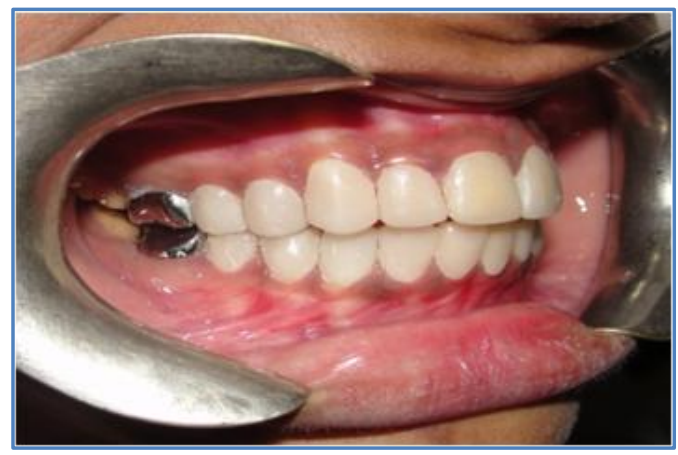

Fig.13: Cemented restoration right lateral view

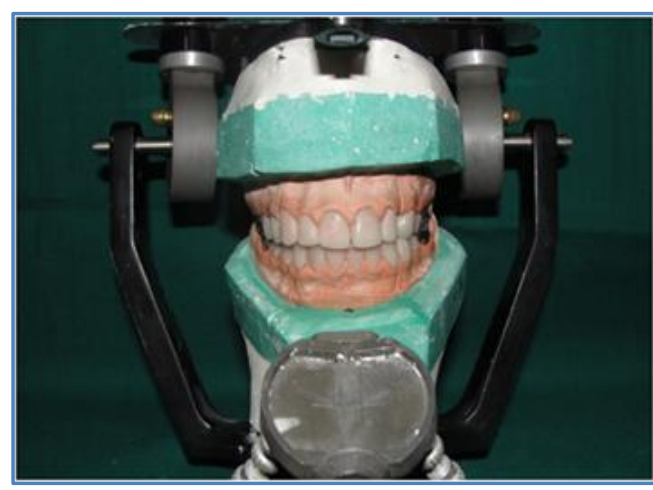

Fig.12: Finished restoration frontal view

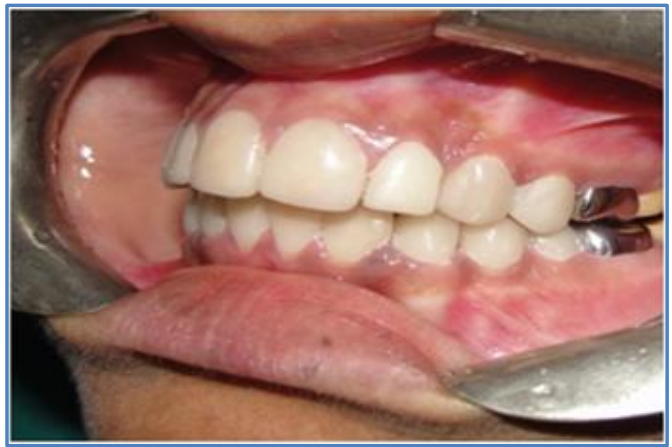

Fig.14: Cemented restoration left lateral view

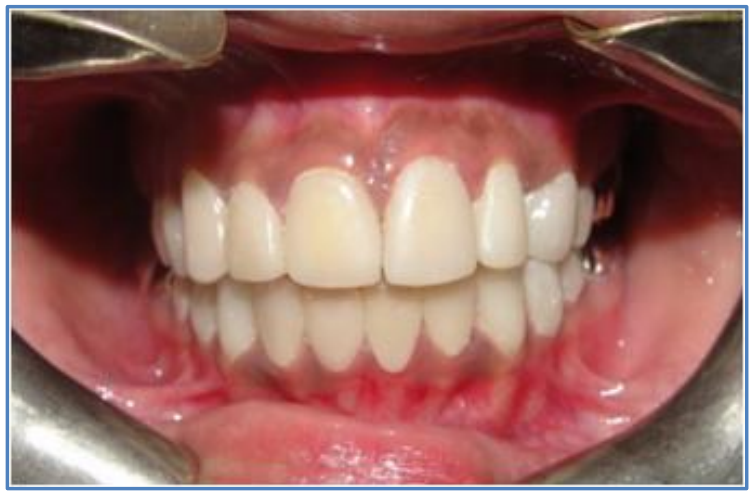

Fig. 15: Cemented restoration frontal view 


\section{AUTHORS:}

1. Veena Hegde

2. Sunanda Sharma

\section{PARTICULARS OF CONTRIBUTORS:}

1. Professor, Department of Prosthodontics, Manipal College of Dental Sciences, Manipal, Manipal University, Karnataka.

2. Former Post Graduate, Department of Prosthodontics, Manipal College of Dental Sciences, Manipal, Manipal University, Karnataka.

\section{NAME ADDRESS EMAIL ID OF THE} CORRESPONDING AUTHOR:

Dr. Veena Hegde,

Shrigandha, 1-71C,

Budnar, Opposite to MGM College,

Kunjibettu-576102, Udupi,

Udupi District, Karnataka, India.

E-mail: drveenahebbar@yahoo.com

Date of Submission: 13/12/2014.

Date of Peer Review: 14/12/2014.

Date of Acceptance: 24/12/2014.

Date of Publishing: 01/01/2015. 